\title{
A time series analysis of meteorological factors and hospital outpatient admissions for cardiovascular disease in the Northern district of Guizhou Province, China
}

\author{
Y. Jie ${ }^{1}$, H. Houjin ${ }^{1}$, Y. Mengxue ${ }^{2}$, Q. Wei ${ }^{3}$ and X. Jie ${ }^{1}$ \\ ${ }^{1}$ School of Public Health, Zunyi Medical University, Zunyi, Guizhou, China \\ ${ }^{2}$ Department of Endocrinology, Affiliated Hospital of Zunyi Medical University, Zunyi, Guizhou, China \\ ${ }^{3}$ Department of Physiology, Zunyi Medical University, Zunyi, Guizhou, China
}

\begin{abstract}
Findings on the effects of weather on health, especially the effects of ambient temperature on overall morbidity, remain inconsistent. We conducted a time series study to examine the acute effects of meteorological factors (mainly air temperature) on daily hospital outpatient admissions for cardiovascular disease (CVD) in Zunyi City, China, from January 1, 2007 to November 30, 2009. We used the generalized additive model with penalized splines to analyze hospital outpatient admissions, climatic parameters, and covariate data. Results show that, in Zunyi, air temperature was associated with hospital outpatient admission for CVD. When air temperature was less than $10^{\circ} \mathrm{C}$, hospital outpatient admissions for CVD increased 1.07-fold with each increase of $1^{\circ} \mathrm{C}$, and when air temperature was more than $10^{\circ} \mathrm{C}$, an increase in air temperature by $1^{\circ} \mathrm{C}$ was associated with a 0.99-fold decrease in hospital outpatient admissions for CVD over the previous year. Our analyses provided statistically significant evidence that in China meteorological factors have adverse effects on the health of the general population. Further research with consistent methodology is needed to clarify the magnitude of these effects and to show which populations and individuals are vulnerable.
\end{abstract}

Key words: Temperature; Cardiovascular disease; Hospital outpatient admission

\section{Introduction}

Numerous epidemiological studies have confirmed that short-term exposure to climatic change contributes to increased cardiorespiratory morbidity (1-4). Among the meteorological parameters, air temperature has the most consistent association with morbidity $(5,6)$. Overall mean temperature as well as extreme weather events across the planet are projected to increase, according to future climate simulations (7). Therefore, definition of the effects of meteorological variables on population health is regarded as important in the governmental policy-making process.

Although the effects of high or low environmental temperatures on mortality have been well documented (8-10), there is much less evidence about the effects of air temperature on morbidity. Studies of heat waves tend to show comparatively smaller increases in hospital admissions than in mortality $(11,12)$, but the results of time series studies are not consistent. In New York City, there was an association between hot weather and a rise in hospital admissions for cardiovascular disorders in the elderly (13). In Germany, a relationship between temperature and the occurrence of myocardial infarction was found not only during the winter but also during the summer (14). However, studies performed in London and Madrid found no association between high air temperatures and emergency hospital admissions for cardiovascular disease (CVD) and only a modest increase in admissions for respiratory diseases among the elderly population $(12,15)$. Given the limited and contradictory evidence, further research is needed to increase understanding of the impact of air temperature on morbidity outcomes and to clarify the mechanisms that underlie this association.

The effects of air temperature specifically on CVD morbidity have not been investigated as extensively as the effects on broader outcomes. We aimed to review the evidence for effects of air temperature on the risk of CVD, 
hypothesizing that CVD risk would increase at both the upper and lower extremes of air temperature. The motivation for a focused review of CVD outcomes was two-fold. First, mortality, although investigated frequently as an outcome, is likely to reflect only a small proportion of the total health impact of environmental exposure because many events do not directly result in death. Second, since CVD is a specific outcome with a specific pathophysiology, a clearer description of the effects of temperature on CVD may lead to a better understanding of the potential triggering mechanisms at work among those at high risk of an ischemic event.

Most previous studies were conducted to determine the correlation between meteorological factors and cardiovascular morbidity in developed countries; only a few studies have been conducted in Asia. There is a need for studies in the cities of developing countries because the proportion of vulnerable subgroups living in urban areas is expected to increase as a consequence of continuing growth of the elderly population. The health impact of meteorological factors is thus expected to increase $(16,17)$. The main goal of this study was to increase awareness about the impact of meteorological variables on health in a densely populated area in China, by relating hospital outpatient admissions for CVD to outside air temperature, relative humidity, atmospheric pressure, and rainfall in the urban area of Zunyi during the period from 2007 to 2009

\section{Material and Methods}

\section{Data}

Zunyi, one of the most populous cities in Southwest China, is located beside the Xiangjiang River in Guizhou province. The altitude of the city is approximately 900 meters. The city comprises urban/suburban districts and counties, with a total area of $30,763 \mathrm{~km}^{2}$, and had a population of $6,127,009$ by the end of 2010 . The study area was limited to Honghuagang and Huichuan, the two traditional urban districts of Zunyi, which cover $1,304 \mathrm{~km}^{2}$. The target population included all permanent residents living in this area, which was around 820,000 in 2004.

This retrospective epidemiological study evaluated meteorological data along with daily hospital outpatient admission data for CVD patients living in Zunyi's urban areas. The study data covered the period from January 1, 2007 to November 30, 2009 (1065 days), and were collected from the database of the Statistical Office in Zunyi Medical College. The completeness of the register, the quality of patient diagnosis, and the recorded cause of CVD were examined, and it was demonstrated that the register is both complete and reliable, i.e., all cases of CVD had been confirmed by physicians. The diagnostic groups in this study included all diseases of the circulatory system (ICD-10 codes I00-I99).

Daily climatic data, including air temperature, relative humidity, atmospheric pressure, and rainfall were obtained from the Zunyi County Meteorological Bureau, the government agency in charge of collection of meteorological data in Zunyi. Daily measurements of each meteorological parameter were collected from fixed-site stations located in Honghuagang and Huichuan districts. We extracted 24-h mean, minimum, and maximum air temperatures; relative humidity; and mean, minimum, and maximum atmospheric pressure, and daily rainfall amounts. We only used the actual collected data and did not fill in any missing data in the meteorological indexes.

\section{Statistical analysis}

We investigated associations between air pollution and morbidity using the generalized additive model (GAM) $(18,19)$ with penalized splines to analyze climatic parameters, CVD hospital outpatient admission, and covariate data, while controlling for seasonal and long-term trends, day of the week, and meteorological influences. Because counts of daily CVD hospital outpatient clinic visit data typically follow a Poisson distribution, the core analysis was a GAM.

We incorporated smoothed spline functions of time and weather conditions, which can accommodate nonlinear and nonmonotonic patterns between hospital outpatient admission and weather or time conditions. The partial autocorrelation function was used to select the degrees of freedom for time trend; seven degrees of freedom was selected for the research period in our analyses of CVD hospital outpatient admission. After we established the basic models, we introduced the weather variables (daily mean, minimum, and maximum air temperature; relative humidity; and mean, minimum, and maximum atmospheric pressure and rainfall) and analyzed their effects on CVD hospital outpatient admission. Eight degrees of freedom for daily mean temperature, four degrees of freedom for daily relative humidity, and four degrees of freedom for daily pressure could control for the effects of those parameters on CVD hospital outpatient admission and were used in the model.

Briefly, we fitted the following log-linear generalized additive model:

$$
\begin{aligned}
& Y_{t \mid t e m p, \text { humidity, } \text { pressure }} \sim \text { Poisson }\left(\mu_{t \mid t e m p, \text { humidity, pressure }}\right) \\
& \ln \left(\mu_{t \mid \text { temp }_{t}, \text { humidity }_{t}, \text { pressure }_{t}}\right)=\beta_{0}+n s\left(\text { temp }_{t}, d f_{1}\right) \\
& +n s\left(\text { humidity }_{t}, d f_{2}\right) \\
& +n s\left(\text { pressure }_{t}, d f_{3}\right) \\
& +n s\left(t, d f_{4}\right)
\end{aligned}
$$

where subscript $t$ denotes time of the observation; $t$ temp, humidity, and pressure signify expected daily CVD 
hospital outpatient admissions at time $t ; n s($.$) refers to$ natural cubic spline; $\beta_{0}$ is the intercept term; temp $p_{t}$ refers

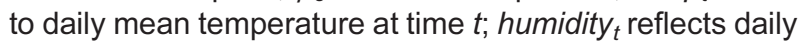

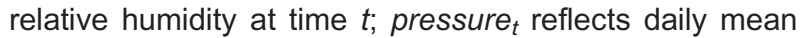
pressure at time $t$; df is degrees of freedom; and $n s(t, d f)$ expresses the change in hospital outpatient numbers with time as a time trend.

Because the air temperature, relative humidity, and atmospheric pressure variables in this study belong to a time series, from the perspective of forecasting, they can be explained and forecasted by a time trend function with a high degree of freedom. Therefore, if the degree of freedom of the time trend function chosen was too high, variations in air temperature, relative humidity, and atmospheric pressure could be accounted for. When the degree of freedom of the time trend function was 200 , the variations in air temperature, relative humidity, and atmospheric pressure curves were almost horizontal.

The principle of our study was to smooth the time trend curve without disturbing the existing curve. Under the premise that there were no obvious effects on other factors, we tried to fit the model better. If degrees of freedom of the time trend function ranged from four to seven, under the precondition of no obvious effects on air temperature, relative humidity, and atmospheric pressure, we tried to choose a high degree of freedom.

In order to facilitate interpretation of the regression results, we developed two definitions as follows:

temp $1=\left\{\begin{array}{cl}\text { temp } & \text { if temp }<10 \\ 10 & \text { if temp } \geq 10\end{array}\right.$

temp2 $=\left\{\begin{array}{cc}0 & \text { if temp }<10 \\ \text { temp }-10 & \text { if temp } \geq 10\end{array}\right.$

We used relative humidity and atmospheric pressure as independent variables. All model analyses were performed using $R$, version 2.5.0, using the mgcv package, 1.3-24, which provides functions for GAMs (20).

\section{Results}

\section{Data description}

Daily temperature, humidity, pressure, rainfall, and CVD hospital outpatient admissions. The frequency distribution of daily mean, minimum, and maximum air temperature; relative humidity; and daily mean, minimum, and maximum atmospheric pressure, rainfall, and CVD hospital outpatient admissions are shown in Table 1. Daily mean values of air temperature were plotted for the entire period from January 1, 2007 through November 30,2009 to graphically display trends in ambient temperature levels over time. As expected, a distinctive cyclic pattern was readily seen, with higher values occurring in the summer/fall months and lower values in the winter/spring.

\section{Regression results}

Comparing four with seven degrees of freedom for the time trend function, we considered the variations in air temperature, relative humidity, and atmospheric pressure of both degrees of freedom as small. Hence, we selected seven as the degrees of freedom for the time trend function after a first exploratory analysis. It is hard to explain why the curve was obviously disturbed when the air temperature ranged from 15 to $25^{\circ} \mathrm{C}$ (see Figure 1). The curve "bounced" when air temperature ranged from 15 to $25^{\circ} \mathrm{C}$, and the changes in the curve may reflect the comparative ease of patients to visit the hospital outpatient clinic and to a reduction in rainfall for the air temperature variation range studied (see Figure 2).

When air temperature ranged from 15 to $25^{\circ} \mathrm{C}$, humidity decreased sharply with an increase in air temperature; therefore, the "bounce" phenomenon of hospital outpatient admission can be explained if local air temperature was within that temperature range, and rainfall was obviously reduced (see Figure 3). Both atmospheric pressure and air temperature decreased linearly (see Figure 4).

Table 1. Frequency distribution of daily air temperature, relative humidity, atmospheric pressure, rainfall and cardiovascular disease hospital outpatient admission from January 1, 2007 to November 11, 2009 in Zunyi, China.

\begin{tabular}{lcccccc}
\hline Variable & Mean $\pm \mathrm{SE}$ & Minimum & P25 & P50 & P75 & Maximum \\
\hline Daily mean temperature $\left({ }^{\circ} \mathrm{C}\right)$ & $15.66 \pm 7.73$ & -4.50 & 9.95 & 16.70 & 22.40 & 28.1 \\
Daily minimum temperature $\left({ }^{\circ} \mathrm{C}\right)$ & $13.10 \pm 9.10$ & -5.20 & 7.45 & 13.90 & 19.30 & 25.70 \\
Daily maximum temperature $\left({ }^{\circ} \mathrm{C}\right)$ & $19.97 \pm 12.26$ & -3.80 & 13.40 & 20.60 & 27.50 & 33.80 \\
Relative humidity $(\%)$ & $75.05 \pm 12.47$ & 16.00 & 68.00 & 76.00 & 85.00 & 96.00 \\
Daily mean pressure $(\mathrm{hPa})$ & $905.70 \pm 6.42$ & 886.30 & 900.50 & 905.50 & 910.45 & 921.30 \\
Daily minimum pressure $(\mathrm{hPa})$ & $902.82 \pm 6.85$ & 881.90 & 897.70 & 902.30 & 907.45 & 917.90 \\
Daily maximum pressure $(\mathrm{hPa})$ & $907.86 \pm 6.58$ & 891.70 & 902.60 & 907.70 & 912.70 & 924.00 \\
Rainfall (mm) & $6.26 \pm 11.77$ & 0 & 0.50 & 1.85 & 6.65 & 91.40 \\
Cardiovascular disease & $44.57 \pm 40.57$ & 0 & 0 & 48 & 73 & 175 \\
\hline
\end{tabular}




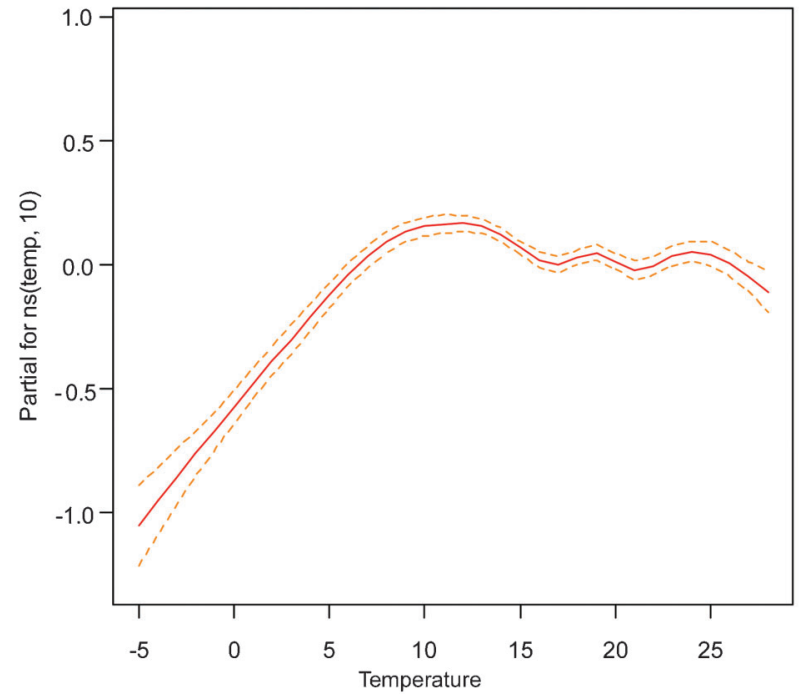

Figure 1. Air temperature effect graph (10 degrees of freedom).

According to the above analysis, we considered eight as the degrees of freedom for air temperature natural spline function, four as the degrees of freedom for the relative humidity spline function, and four as the degrees of freedom for the atmospheric pressure spline function. The day of the week effect was obvious, showing that hospital outpatient admissions were the lowest on Thursdays (see Figures 2,5-8).

When the air temperature was less than $10^{\circ} \mathrm{C}$, hospital outpatient admissions for CVD increased by $\exp (0.0700132)=1.0725223$-fold for an increase of $1^{\circ} \mathrm{C}$; when air temperature was more than $10^{\circ} \mathrm{C}$, an increase in

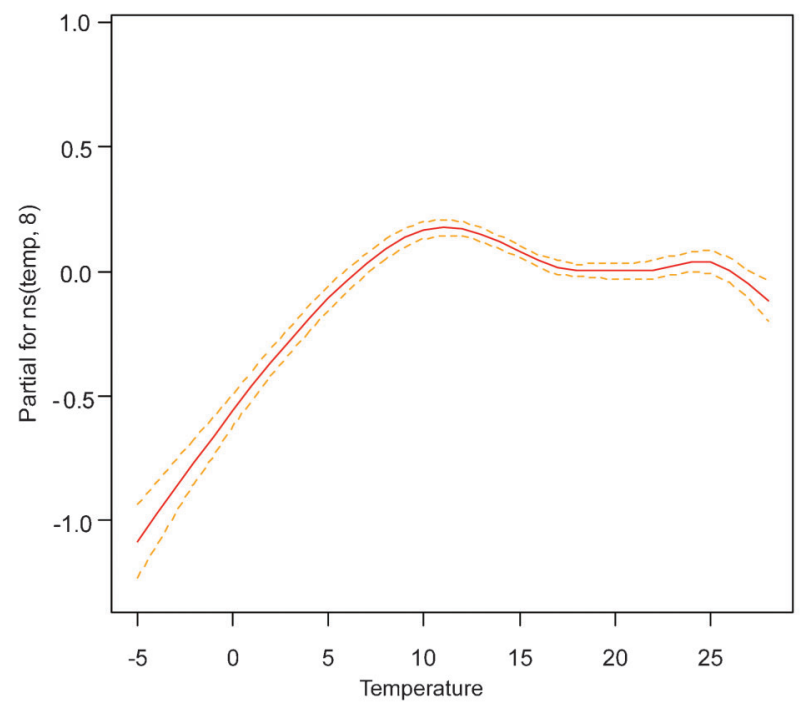

Figure 2. Air temperature effect graph (8 degrees of freedom).

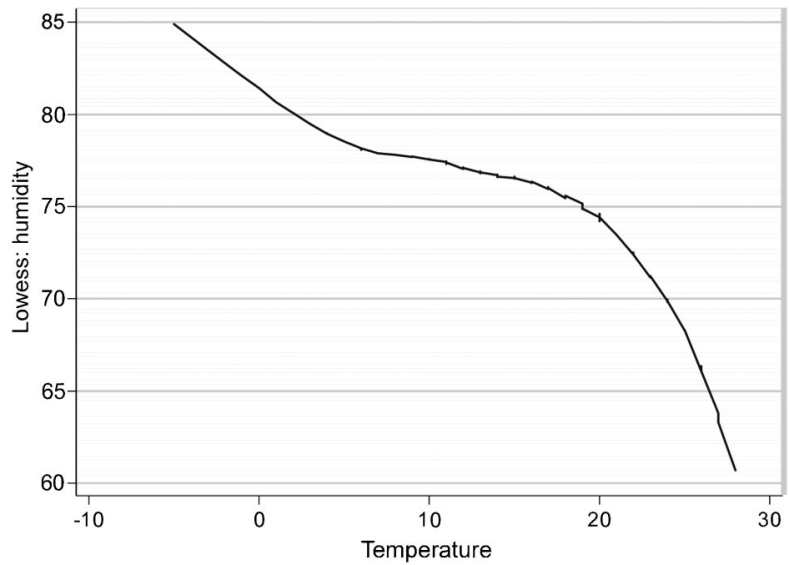

Figure 3. Relative humidity and air temperature linear association.

temperature by $1^{\circ} \mathrm{C}$ was associated with a decrease in hospital outpatient admissions for CVD, which was $\exp (-0.0092349)=0.99080761$-fold over the previous year (see Table 2).

\section{Discussion}

As reflected in the literature, the relationship between hospital admissions for CVD and climate is probably very complex and modulated by several factors. Nonetheless, a clear relationship was observed in this study between hospital outpatient admissions for CVD and climatic conditions. Variables corresponding to daily mean air temperature, relative humidity, atmospheric pressure, and rainfall were among the first to be selected in the GAM, confirming a cumulative effect of weather variations on CVD. To our knowledge, few studies in China have investigated the effects of meteorological factors on daily

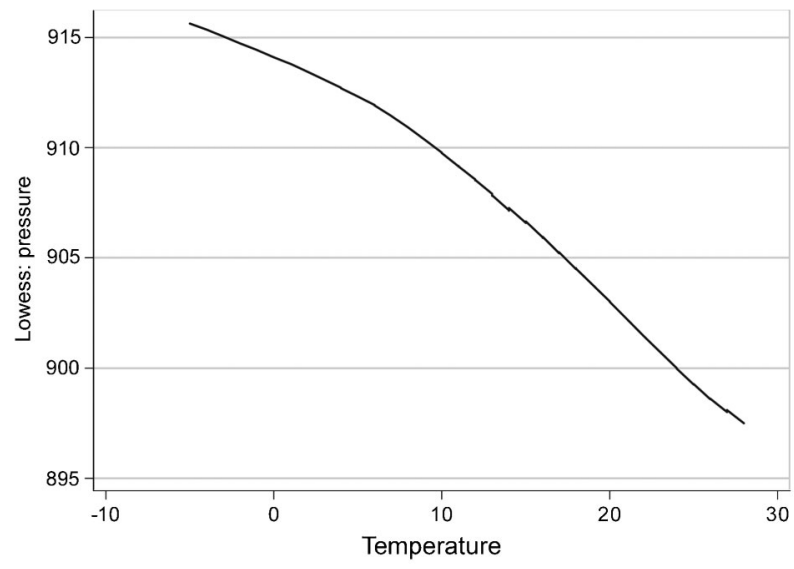

Figure 4. Atmospheric pressure and air temperature linear association. 


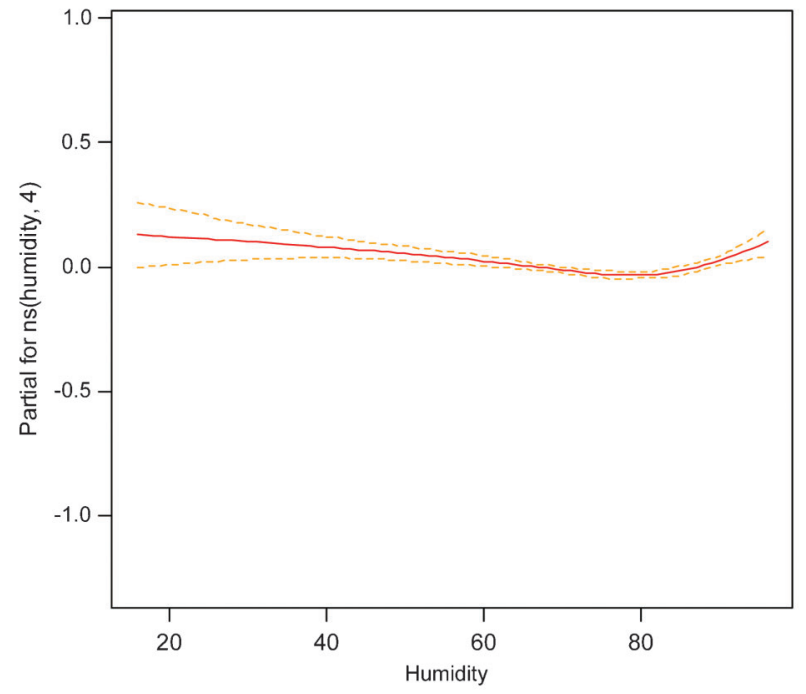

Figure 5. Relative humidity effect graph (4 degrees of freedom).

hospital outpatient admissions for CVD. Our results should contribute to the understanding of climatic variations and weather-related health effects in China.

In the present study, we reported the relationship of exposure to different climatic conditions on health effects using hospital outpatient data on cardiovascular outcomes, because we considered outpatient data a more sensitive indicator of the acute health effects of climatic conditions than inpatient data. Consistent with several prior studies in the United States (21), Canada (22), Japan (23), and Europe $(24,25)$, we found significant effects of temperature on cardiovascular outcomes using

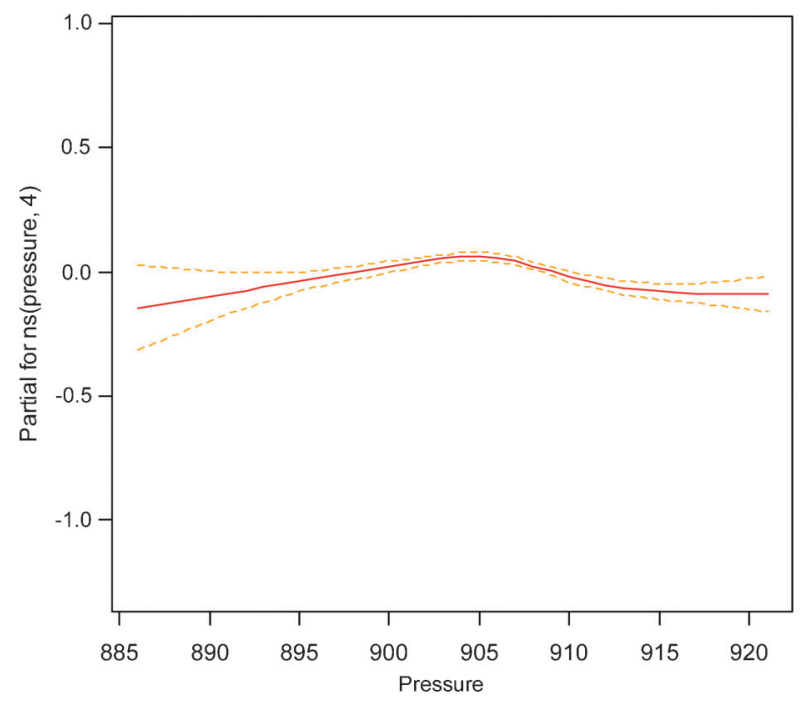

Figure 6. Atmospheric pressure effect graph (4 degrees of freedom).

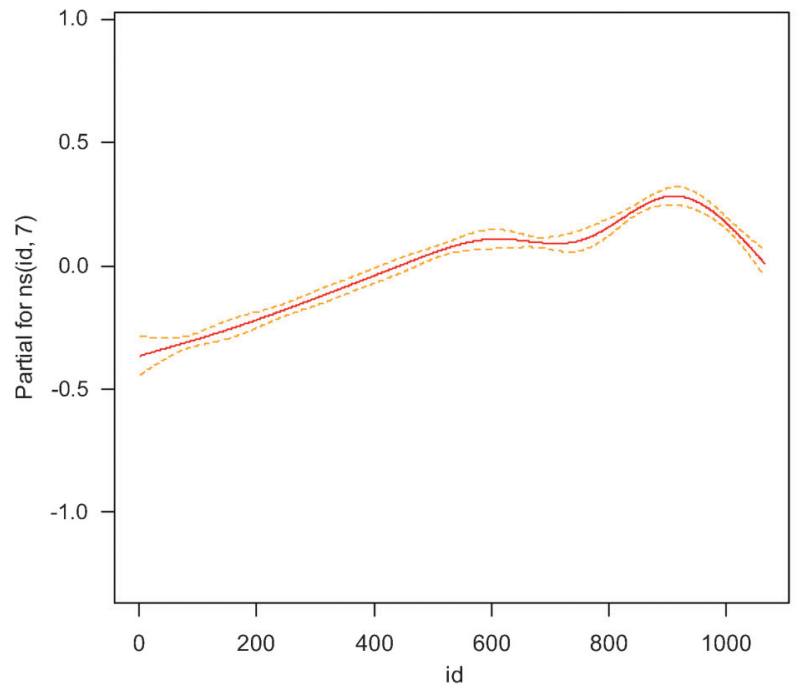

Figure 7. Time trend function (7 degrees of freedom).

GAM analysis. Schwartz et al. (21) estimated meteorological exposure using Poisson regression models, and they found that, for cities in cold climates, hospital admissions for all heart diseases increased monotonically with mean temperature on the same day as, and the day before, admission. Bayentin et al. (22) used the GAM statistical model and found that cold temperatures during the winter months and hot episodes during the summer months are associated with increases of up to $12 \%$ in daily hospital admission rates for ischemic heart disease.

Compared with prior results of a systematic review (26) and the multicity analyses mentioned above, our

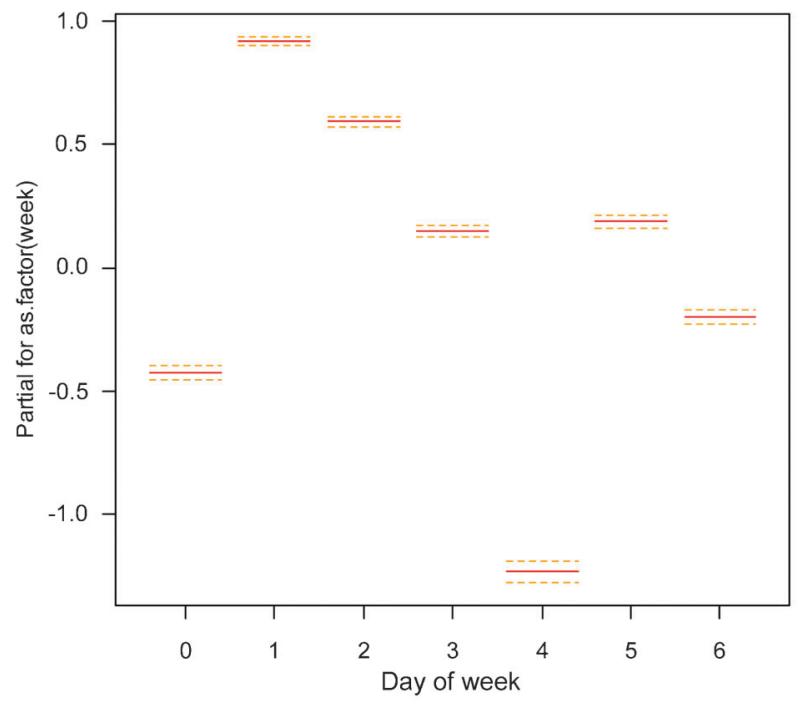

Figure 8. Effect of the day of the week (0: Sunday; 1 : Monday; 2 : Tuesday; 3: Wednesday; 4: Thursday; 5: Friday; 6: Saturday). 
Table 2. Coefficient parameter estimates in generalized additive model.

\begin{tabular}{|c|c|c|c|c|}
\hline Coefficients & Estimate & SE & $z$ value & $\operatorname{Pr}(>|z|)$ \\
\hline (Intercept) & 2.8214673 & 1.0915981 & 2.585 & $0.00975^{*}$ \\
\hline Temp1 & 0.0700132 & 0.0024077 & 29.079 & $0.00000^{* *}$ \\
\hline Temp2 & -0.0092349 & 0.0013304 & -6.942 & $0.00000^{* *}$ \\
\hline Humidity & 0.0002780 & 0.0004049 & 0.687 & 0.49237 \\
\hline Pressure & 0.0000316 & 0.0011877 & 0.027 & 0.97877 \\
\hline $\mathrm{ns}(\mathrm{id}, 4) 1$ & 0.3961896 & 0.0254677 & 15.557 & $0.00000^{* *}$ \\
\hline ns(id, 4)2 & 0.5362057 & 0.0239745 & 22.366 & $0.00000^{* *}$ \\
\hline ns(id, 4)3 & 0.6784606 & 0.0548579 & 12.368 & $0.00000^{* *}$ \\
\hline $\mathrm{ns}(\mathrm{id}, 4) 4$ & 0.4106398 & 0.0213794 & 19.207 & $0.00000^{* *}$ \\
\hline
\end{tabular}

See text for explanation of Temp1 and Temp2. ${ }^{*} \mathrm{P}<0.01$; ${ }^{*} \mathrm{P}<0.001$ (linear regression).

estimates in Zunyi were different. This may reflect differences in the characteristics of the study sites in addition to the statistical techniques that we used. Local climatic conditions, population sensitivity to climatic variation, and age distributions may strongly affect exposure-response relationships. The climate in Zunyi is humid and subtropical with a monsoon season. Unseasonably warm or cold spells are common, although temperatures rarely reach extremes, and rain falls throughout the year. It is also one of China's least sunny cities. Topography, meteorology, and air pollution exacerbate the ambient air quality conditions of Zunyi, and the mountains of up to $1250 \mathrm{~m}$ in height that surround Zunyi inhibit the dispersion of air pollutants. In addition, consistent with several recent time series studies (2729), we used the penalized spline model for our data analysis, whereas most previous temperature time series studies have been based on the GAM in S-PLUS.

A major finding of the present study was that when the air temperature was less than $10^{\circ} \mathrm{C}$, hospital outpatient admissions for CVD increased 1.07-fold with each increase of $1^{\circ} \mathrm{C}$ and, when air temperature was more than $10^{\circ} \mathrm{C}$, an increase in temperature by $1^{\circ} \mathrm{C}$ was associated with a decrease in hospital outpatient admissions for CVD, which was 0.99 -fold over the past year. The results indicated that low winter temperatures are a trigger for CVD in Zunyi. This is in contrast to most studies in Western countries that have focused on mortality and report a nonlinear relation (U-, J-, or V-shaped) between daily mortality and extreme temperatures (22,30-32). A study conducted in the Netherlands that focused on morbidity similarly reported a J-shaped relation. They found that the low-temperature effect on CVD was slightly greater than that on mortality from all causes, while the impact of high temperature was the opposite (33). Therefore, low temperatures may have a greater impact on CVD. The annual average temperature in Zunyi is roughly 10 to $20^{\circ} \mathrm{C}$, and one innovation of our study is that we found a positive correlation between temperature and hospital outpatient admission below a threshold temperature, and a negative correlation of these two variables above the threshold temperature. There was no nonlinear relation (U-, J-, or $\mathrm{V}$-shaped) between the two variables compared to other studies, and we clarified the magnitude of the effects of temperature on CVD among the study population. The variation pattern in our study was consistent with CVD seasonal variations, and the changeable pattern may be associated with seasonal variations in Zunyi and the seasonal variation patterns of temperature, blood pressure, lipids, fibrinogen level, and infection among the population. Cold weather may be important because cold conditions can lead to increases in systolic blood pressure, central blood volume, and heme concentration, as well as a reduction in the body's thermoregulatory efficiency. During exposure to a hyperthermic environment, systemic vascular resistance normally decreases due to cutaneous vasodilation. Cardiac output must increase to maintain blood pressure. Patients will either not maintain blood pressure or will not vasodilate the skin adequately for thermoregulation, the latter of which will increase the risk for heat-related injuries (34). In addition, increase in fibrinogenemia during the cold months could contribute to an increased occurrence of CVD in winter (35). These findings provide possible pathways by which air temperature can affect the cardiovascular system. Zunyi offers advantages for the investigation of a temperaturemorbidity relationship. Our study area, two urban districts of Zunyi, is densely populated. More than 820,000 permanent residents reside within $1365 \mathrm{~km}^{2}$. In addition, compared with residents of North America, a lower proportion of Zunyi residents have access to or use air conditioning. Thus, the monitored meteorological data from the winter months may be more closely associated with average population exposures in Zunyi than in cities in North America.

There are a number of study limitations. Because the health data were from existing administrative databases, patient history of heart disease, personal habits such as smoking, and comorbidities could not be taken into account. Another limitation of our study was our inability to distinguish between new and repeated admissions, which could lead to increased rates of hospitalization. 
Hospitalization rates obtained for the first-listed diagnosis may underrepresent the actual number of admissions associated with a specific disease. Our study also did not assess the role of air pollution in the genesis of CVD episodes, although such a role seems significant $(36,37)$. In accordance with the study protocol, only the main discharge diagnosis was considered, and this could have influenced our results.

In summary, we found significant associations between the number of hospital outpatient visits and meteorological factors (mainly air temperature) in Zunyi. When air temperature was less than $10^{\circ} \mathrm{C}$, hospital outpatient admissions for CVD increased 1.07-fold with an increase of $1^{\circ} \mathrm{C}$; when air temperature was more than $10^{\circ} \mathrm{C}$, an increase in temperature of $1^{\circ} \mathrm{C}$ was associated with a 0.99 fold decrease in hospital outpatient admissions for CVD,

\section{References}

1. Yu Jie, Isa ZM, Jie X, Ismai NH. Asthma and asthma-related symptoms among adults of an acid rain-plagued city in Southwest China: Prevalence and risk factors. Pol J Environ Stud 2013; 22: 717-726.

2. Jie $Y$, Ismail $N H$, Jie $X$, Isa $Z M$. Do indoor environments influence asthma and asthma-related symptoms among adults in homes?: A review of the literature. J Formos Med Assoc 2011; 110: 555-563, doi: 10.1016/j.jfma.2011.07.003.

3. Jie $\mathrm{Y}$, Houjin $\mathrm{H}$, Feng J, Jie $\mathrm{X}$. The role of airborne microbes in school and its impact on asthma, allergy and respiratory symptoms among school children. Rev Med Microbiol 2011; 22: 84-89, doi: 10.1097/MRM.0b013e32834a449c.

4. Zeng W, Lao X, Rutherford S, Xu Y, Xu X, Lin H, et al. The effect of heat waves on mortality and effect modifiers in four communities of Guangdong Province, China. Sci Total Environ 2014; 482-483C: 214-221, doi: 10.1016/j.scitotenv. 2014.02.049.

5. Jie $Y$, Ju ZL, Li LX, Hai J, Jie X. The impact of ambient temperature on pulmonary morbidity among the urban population in Zunyi, China. Pol J Environ Stud 2013; 22: 707-716.

6. Mostofsky E, Wilker EH, Schwartz J, Zanobetti A, Gold DR, Wellenius GA, et al. Short-term changes in ambient temperature and risk of ischemic stroke. Cerebrovasc Dis Extra 2014; 4: 9-18, doi: 10.1159/000357352.

7. Schnoor JL. The IPCC fourth assessment. Environ Sci Technol 2007; 41: 1503, doi: 10.1021/es072475x.

8. Harlan SL, Chowell G, Yang S, Petitti DB, Morales Butler EJ, Ruddell BL, et al. Heat-related deaths in hot cities: estimates of human tolerance to high temperature thresholds. Int J Environ Res Public Health 2014; 11: 3304-3326, doi: 10.3390/ijerph110303304.

9. Azhar GS, Mavalankar D, Nori-Sarma A, Rajiva A, Dutta P, Jaiswal $A$, et al. Heat-related mortality in India: excess all-cause mortality associated with the 2010 ahmedabad heat wave. PLoS One 2014; 9: e91831, doi: 10.1371/journal.pone. 0091831.

10. Ng CF, Ueda K, Takeuchi A, Nitta H, Konishi S, Bagrowicz $R$, et al. Sociogeographic variation in the effects of heat and cold on daily mortality in Japan. J Epidemiol 2014; 24: over the previous year. Our analyses provide statistically significant evidence that, in China, meteorological factors have an adverse effect on the health of the general population, and further research with consistent methodology is needed to clarify the magnitude of these effects and to show which populations and individuals are most vulnerable.

\section{Acknowledgments}

Research supported by National Natural Science Foundation of China (\#2013-81360419) and Key Technologies Research and Development Program of the Department of Science and Technology of Guizhou Province, China (\#SY[2013]3027, \#SY[2012]3126, and \#SY[2011]3029).

\section{5-24, doi: 10.2188/jea.JE20130051.}

11. Semenza JC, McCullough JE, Flanders WD, McGeehin MA Lumpkin JR. Excess hospital admissions during the July 1995 heat wave in Chicago. Am J Prev Med 1999; 16: 269277, doi: 10.1016/S0749-3797(99)00025-2.

12. Kovats RS, Hajat S, Wilkinson P. Contrasting patterns of mortality and hospital admissions during hot weather and heat waves in Greater London, UK. Occup Environ Med 2004; 61: 893-898, doi: 10.1136/oem.2003.012047.

13. Lin S, Luo M, Walker RJ, Liu X, Hwang SA, Chinery R. Extreme high temperatures and hospital admissions for respiratory and cardiovascular diseases. Epidemiology 2009; 20: 738-746, doi: 10.1097/EDE.0b013e3181ad 5522.

14. Wolf K, Schneider A, Breitner S, von Klot S, Meisinger C, Cyrys $\mathrm{J}$, et al. Air temperature and the occurrence of myocardial infarction in Augsburg, Germany. Circulation 2009; 120: 735742, doi: 10.1161/CIRCULATIONAHA.108.815860.

15. Linares C, Diaz J. Impact of high temperatures on hospital admissions: comparative analysis with previous studies about mortality (Madrid). Eur J Public Health 2008; 18: 317322, doi: 10.1093/eurpub/ckm108.

16. Guo $Y$, Jia $Y$, Pan $X$, Liu L, Wichmann HE. The association between fine particulate air pollution and hospital emergency room visits for cardiovascular diseases in Beijing, China. Sci Total Environ 2009; 407: 4826-4830, doi 10.1016/j.scitotenv.2009.05.022.

17. Jie $\mathrm{Y}$, Isa ZM, Jie $\mathrm{X}$, Ju ZL, Ismail NH. Urban vs rural factors that affect adult asthma. Rev Environ Contam Toxicol 2013; 226: 33-63.

18. Wang MZ, Zheng S, He SL, Li B, Teng HJ, Wang SG, et al. The association between diurnal temperature range and emergency room admissions for cardiovascular, respiratory, digestive and genitourinary disease among the elderly: a time series study. Sci Total Environ 2013; 456-457: 370375, doi: 10.1016/j.scitotenv.2013.03.023.

19. Saenz-de-Miera O, Rosselló J. Modeling tourism impacts on air pollution: The case study of PM10 in Mallorca. Tourism Manage 2014; 40: 273-281, doi: 10.1016/j.tourman.2013. 06.012 . 
20. The R Foundation for Statistical Computing. http://www.r-project. org/. Accessed July 15, 2013.

21. Schwartz J, Samet JM, Patz JA. Hospital admissions for heart disease: the effects of temperature and humidity. Epidemiology 2004; 15: 755-761, doi: 10.1097/01.ede. 0000134875.15919.0f.

22. Bayentin L, El Adlouni S, Ouarda TB, Gosselin P, Doyon B, Chebana F. Spatial variability of climate effects on ischemic heart disease hospitalization rates for the period 1989-2006 in Quebec, Canada. Int J Health Geogr 2010; 9: 5, doi: 10.1186/1476-072X-9-5

23. Wang H, Matsumura M, Kakehashi M, Eboshida A. Effects of atmospheric temperature and pressure on the occurrence of acute myocardial infarction in Hiroshima City, Japan. Hiroshima J Med Sci 2006; 55: 45-51.

24. Morabito M, Crisci A, Grifoni D, Orlandini S, Cecchi L, Bacci $\mathrm{L}$, et al. Winter air-mass-based synoptic climatological approach and hospital admissions for myocardial infarction in Florence, Italy. Environ Res 2006; 102: 52-60, doi: 10.1016/j.envres.2005.12.007.

25. Panagiotakos DB, Chrysohoou C, Pitsavos C, Nastos P, Anadiotis A, Tentolouris $C$, et al. Climatological variations in daily hospital admissions for acute coronary syndromes. Int J Cardiol 2004; 94: 229-233, doi: 10.1016/j.ijcard. 2003.04.050.

26. Bhaskaran $\mathrm{K}$, Hajat $\mathrm{S}$, Haines A, Herrett E, Wilkinson $\mathrm{P}$, Smeeth $\mathrm{L}$. Effects of ambient temperature on the incidence of myocardial infarction. Heart 2009; 95: 1760-1769, doi: 10.1136/hrt.2009.175000.

27. Huang W, Kan H, Kovats S. The impact of the 2003 heat wave on mortality in Shanghai, China. Sci Total Environ 2010; 408: 2418-2420, doi: 10.1016/j.scitotenv.2010.02. 009.

28. Almeida SP, Casimiro E, Calheiros J. Effects of apparent temperature on daily mortality in Lisbon and Oporto, Portugal. Environ Health 2010; 9: 12, doi: 10.1186/1476-069 $\mathrm{X}-9-12$.

29. Arena VC, Mazumdar S, Zborowski JV, Talbott EO, He S, Chuang $\mathrm{YH}$, et al. A retrospective investigation of PM10 in ambient air and cardiopulmonary hospital admissions in
Allegheny County, Pennsylvania: 1995-2000. J Occup Environ Med 2006; 48: 38-47, doi: 10.1097/01.jom. 0000183096.20678.f1.

30. Curriero FC, Heiner KS, Samet JM, Zeger SL, Strug L, Patz JA. Temperature and mortality in 11 cities of the eastern United States. Am J Epidemiol 2002; 155: 80-87, doi: 10.1093/aje/155.1.80.

31. Leone M, D'Ippoliti D, De Sario M, Analitis A, Menne B, Katsouyanni K, et al. A time series study on the effects of heat on mortality and evaluation of heterogeneity into European and Eastern-Southern Mediterranean cities: results of EU CIRCE project. Environ Health 2013; 12: 55, doi: 10.1186/1476-069X-12-55.

32. Wu W, Xiao Y, Li G, Zeng W, Lin H, Rutherford S, et al. Temperature-mortality relationship in four subtropical Chinese cities: a time-series study using a distributed lag non-linear model. Sci Total Environ 2013; 449: 355-362, doi: 10.1016/j.scitotenv.2013.01.090.

33. Mackenbach JP, Kunst AE, Looman CW. Seasonal variation in mortality in The Netherlands. J Epidemiol Community Health 1992; 46: 261-265, doi: 10.1136/jech.46.3.261.

34. Oktay C, Luk JH, Allegra JR, Kusoglu L. The effect of temperature on illness severity in emergency department congestive heart failure patients. Ann Acad Med Singapore 2009; 38: 1081-1084.

35. Woodhouse PR, Khaw KT, Plummer M, Foley A, Meade TW. Seasonal variations of plasma fibrinogen and factor VII activity in the elderly: winter infections and death from cardiovascular disease. Lancet 1994; 343: 435-439, doi: 10.1016/S0140-6736(94)92689-1.

36. Rodopoulou S, Chalbot MC, Samoli E, Dubois DW, San Filippo BD, Kavouras IG. Air pollution and hospital emergency room and admissions for cardiovascular and respiratory diseases in Dona Ana County, New Mexico. Environ Res 2014; 129: 39-46, doi: 10.1016/j.envres. 2013.12.006.

37. Vanos JK, Hebbern C, Cakmak S. Risk assessment for cardiovascular and respiratory mortality due to air pollution and synoptic meteorology in 10 Canadian cities. Environ Pollut 2014; 185: 322-332, doi: 10.1016/j.envpol.2013.11.007. 